\title{
A study of relationship between emotional intelligence and innovative work behavior of managers
}

\author{
Mohammad Reza Shojaei $^{\mathrm{a}}$ and Mohadeseh Emadi Siuki ${ }^{\mathbf{*}}$
}

${ }^{a}$ Assistant Professor, Department of Management and Accounting, Shahid Beheshti University, Tehran, Iran ${ }^{b}$ MSc Student in Business Management, Ershad institute of Higher Education, Tehran, Iran

\section{H R O N I C L E}

Article history:

Received January 4, 2014

Accepted 1 June 2014

Available online

June 112014

Keywords:

Emotional intelligence

Innovative work behavior

Managers

\section{A B S T R A C T}

This paper studies the relationship between emotional intelligence and its components, selfawareness, self-management, social-awareness and relationship-management, with managers' innovative work behavior. The research statistical population includes 100 managers of private bank branches in the city of Tehran selected with the random sampling method. The research type is descriptive-correlation. The tool for data aggregation is comprised of two questionnaires of emotional intelligence by Bradberry and Greaves (2006) [Bradberry, T., \& Greaves, J. (2006). The emotional intelligence quick book: Everything you need to know to put your EQ to work. Simon and Schuster.] and innovative work behavior based on the studies of Janssen (2000) [Janssen, O. (2000). Job demands, perceptions of effort-reward fairness and innovative work behaviour. Journal of Occupational and organizational psychology, 73(3), 287-302.]. The Pearson correlation coefficient and multiple regression analysis have been used for data analysis. The results indicated that there was a positive and significant relationship between emotional intelligence and its components with innovative work behavior of managers. In addition, regression analysis showed that the self-management variable had the highest effect in estimating the managers' innovative work behavior followed by relationship-management, selfawareness and social-awareness.

\section{Introduction}

In today's turbulent world in which many organizations are subjected to change, the survival and the success of them is pawned to innovation, flexibility, responding and the productivity of all active classes of the society. Therefore, employees and managers represent innovative power and thoughts so that they could lead the objectives and the strategies of the organization to the final destination (Aghaei Fishani, 1999). In order to materialize the micro and macro objectives of organizations, managers are required to have attributes and traits to carry the innovative thoughts to emergence destinations. Emotional intelligence is one of the attributes that could help significantly in the field of designing and the novel thoughts, compromise and conformity with the fresh conditions to the 
managers especially, in the context of decision making during the crisis and unknown situations (Steiner, 2007). On the other hand, the effective and productive decision-making has been one of the most important managerial subjects, which enables managers to access the goals that cause the advancement of the organization. Therefore, to materialize such a goal, an efficient leader and guide as a decision maker, must have the high emotional intelligence. According to Hayashi and Ewert (2006), the more the emotional intelligence, the better and more effective is the performance. In addition, the individuals who have the emotional skill i.e. the people who better identify and direct their emotions and perceive the feelings of others and encounter it effectively, are distinctive in every scope of life, whether it is in affective and sincere relations, or in the understanding of unsaid that leads to the progress of organizational policy. Besides, the emotional intelligence is a form of intelligence, which has been the combination of emotions and thinking and gives the meaning of looking into the general structure of personal and social emotions' abilities. It also influences on the aptitude, encounters with the requests and the peripheral pressures. In addition, the emotional intelligence and the emotional skills grow during time span and can be improved by educating the reformative programs (Bar-On, 2004).

The research results during two last decades indicate that the skills of emotional intelligence are considered as the major factor on the effectiveness of leadership and occupational/job situation of managers and emotional intelligence has high application in all organizational ranks. However, it takes essential significance in the managerial ranks. Therefore, recognition of this phenomenon seems necessary for the managers who play the major roll in supervising and guiding the manpower and finally, the efficiency promotion and the effectiveness of activities. On the other hand, in addition to the emotional intelligence, the innovative work behavior is also considered as one of the important and fundamental attributes for the managers of organizations. In addition to that, considering the present complex and changed conditions and competitiveness of organizations and their encounter with multifaceted challenges of managers, they need to act more innovative than before.

DeJong (2006) defined innovative work behavior (IWB) as “Individuals' behaviors directed toward the initiation and intentional introduction of new and useful ideas, processes, products or procedure within a work role, group or organization.”. In addition, the innovative work behavior is a dynamic and complex phenomenon that also encompasses the creativity.

Until now, much research has been done in the field of emotional intelligence, however, the modern discussion that is posed in the research related to management and organization, identified as the relation between emotional intelligence and innovative work behavior of the managers. Therefore, the present research studies the relation between emotional intelligence with innovative work behavior of the managers.

\section{Revision on the literature and the research record}

\subsection{Concept of emotional intelligence (EI)}

The word of emotional intelligence is under discussion in the scientific literature for last few years. It has been first discussed in psychology and then in all other sciences in the applied form. Salovey and Mayer (1989) used the word emotional intelligence for the first time. They stated the emotional intelligence as the ability of individual to control the sensations and emotions of self and others, distinguishing between feelings and emotions of self and others in addition to the use of these information for directing the actions and thoughts. They specified the fourfold dimensions of emotional intelligence as follows (Baron and Parker 2000): Self-awareness (awareness of a person of own emotions and sensations), self-management (ability to control the emotions, affections, true, correct and in the reliable manner and conformable behavior), social awareness (distinguishing the thoughts and sensations of others that includes the enjoying of empathy at levels of individual, group and organization), relationship-management (ability to establish the open and acceptable 
communications and relations, eliminate the differences and establishing the powerful bonds/connections among individuals).

Goleman (2006) officially used this word in his book entitled, 'emotional intelligence' during 1995. He suggested that the IQ can only affect the success of people by $20 \%$ and the rest of $80 \%$ was determined by emotional intelligence. He expressed that the emotional intelligence was a skill whose holder could control his/her life essence by the self-awareness, could improve it by self-management, could perceive its effect through empathy and through relationship management could behave in a manner that could heighten the spirits of self and others. He also described that the emotional intelligence was constituted by self-awareness, self-regulation, self-motivation, empathy skill and social skills.

Right now, numerous definitions exist in the context of emotional intelligence. Dulewicz et al. (2003) stated that the emotional intelligence could be defined based on what relates to our awareness of sensations and emotions and administering it, affecting and influencing the others, persisting and balancing the self- motivation and stimulating it through sense, moral and conscientious behavior (Samadi \& Keyvan, 2013). On the other hand, Cherniss and Adlet (2000) stated emotional intelligence as "the ability of controlling the self- emotions, its application in good decision makings and working effectively" (Nwokah \& Ahiauzu, 2010). Bar-On (1997) also considered the emotional intelligence as a set of skills, aptitudes and un-identifying abilities, which increase the success abilities of individual against the pressures and the environmental requirements. The emotional intelligence model of Bar-On includes five components of interpersonal skills, intrapersonal skills, compatibility, stress control and general temperament.

Several studies have been carried out in the field of emotional intelligence. Rahim and Minors (2003), tested three dimensions of emotional intelligence (self-awareness, self-regulation and empathy) with the attention of managers to the products quality, services, and the behavior to solve the problems of subordinates at the time of conflicts' outbreak to study the effect of emotional intelligence on the quality and ability to solve the problem. Their research indicated that self-regulation had direct relation in view of quality, it means, the more the self-regulating is fostered among the managers, the more attention is focused on the service quality. In addition, considering the results of their research the empathy had considerable effect on quality. The self-regulation and empathy also had relatively high interactive effect on quality. Kobe et al. (2001) performed a survey on emotional intelligence effect and social intelligence in developing the ability of leadership. They reported indicated that both emotional intelligence and social intelligence were effective variables in developing the leadership ability in individuals. Also in Iran, Rezaeiyan and Koshtegar (2009) considered the relationship of emotional intelligence and the organizational commitment in the form of a design. They reported that the emotional intelligence had significant relationship with organizational commitment of employees. Among the dimensions of emotional intelligence, the relation management had the maximum effect on organizational commitment. Zeinivand (2009) studied the relationship between emotional intelligence and the performance of middle class teachers and reported that there was a significant relationship among the self-management components, social-awareness and relation management as well as the teachers' performance.

\subsection{Emotional intelligence and Innovative work behavior}

Mumford et al (2002) considered the innovative behavior as presentation and examined some novel ideas including regulation processes and problem analysis, discovery of ideas, development and combination of ideas and their testing in theoretical terms and finally the study of their benefit. Orhan and Dinçer (2012) studied the relationship between emotional intelligence and innovative work behaviors in Turkish banking sector and reported that there was a significant relationship between emotional intelligence and innovative work behavior. In addition to that, there was a significant 
difference between private and governmental banks in terms of emotional intelligence and innovative work behavior.

\section{Research Methodology}

This research is applied in view of its goal, while it is a descriptive-scaling research in terms of data aggregation method. The survey designed a questionnaire to collect the required information. The proposed study considers the following main hypothesis.

Main assumption: There is a significant relationship between emotional intelligence and innovative work behavior of managers.

Sub hypothesis 1: There is a significant relationship between self-awareness and innovative work behavior of managers.

Sub hypothesis 2: There is a significant relationship between self-management and innovative work behavior of managers.

Sub hypothesis 3: There is a significant relationship between social-awareness and innovative work behavior of managers.

Sub hypothesis 4: There is a significant relationship between relation-management and innovative work behavior of managers.

The statistical population of this research includes all heads of private bank in the city of Tehran. Out of this society, a number of 100 managers have been selected and tested using the random sampling method and the determination formula for sample volume. The info collection tool includes two questionnaires, the first questionnaire, is the standard emotional intelligence questionnaire by Bradberry and Greaves (2006), and includes two parts of demographical and specialized questions where the first part accommodates the questions in the context of gender, age, academic qualification. The specialized part of it is comprised of 28 questions out of which 6 questions were on selfawareness, 9 questions on self-management, 5 questions about social awareness, and 8 questions in the field of relationship management. This test assesses four components of emotional intelligence i.e. self-awareness, self-management, social awareness and relationship management. The Janssen (2000) study has been used about IWB questionnaire. The questions of this questionnaire are into two dimensions of creation and testing of novel ideas and implementation. In addition, the scale of options measurement in this test has been based on the scale of five score Likert spectrum (always, mostly, sometimes, rarely, never). The reliability of questionnaires was obtained using the coefficient of Cronbach Alpha respectively for the questionnaire of emotional intelligence and IWB equal to 0.833 and 0.809 that is the indicator of desired reliability of these questionnaires.

After receiving the data, the $20^{\text {th }}$ descriptive and inferential copy was analyzed using the statistical software of SPSS software package. In the descriptive statistical part, first, the collected data was examined in terms of sex, age and academic degree of respondents and the result of each part were specified after that. Among the under study sample, 91 percent are men and 9 percent are women that $2 \%$ of them have bachelor and higher degrees, $51 \%$ bachelor, $47 \%$ diploma. In the context of age distribution of bank managers 1\% of them are in the age limit of 25 to 35 years, $69 \%$ from 35 to 45 years of age, $28 \%$ at the age limit of 45 to 55 while $2 \%$ of them are more than 55 of age. $94 \%$ are married and $6 \%$ single.

In the part of inferential statistics, the Pearson correlation coefficient and the test of its significance have been used to study the relation of emotional intelligence and its components (self-awareness, self-management, social-awareness and the relationship-management) with innovative work behavior. In addition, the multi variable regression analysis has been used for the ability of predictability of emotional intelligence components in terms of innovative work behavior. 
Table 1

Correlations

\begin{tabular}{|c|c|c|c|c|c|c|c|}
\hline Row & Variable & 1 & 2 & 3 & 4 & 5 & 6 \\
\hline 1 & Self-awareness & 1 & & & & & \\
\hline \multirow[t]{2}{*}{2} & Self-management & $0.726 * *$ & 1 & & & & \\
\hline & & 0.000 & & & & & \\
\hline \multirow[t]{2}{*}{3} & Social-Awareness & $0.507 * *$ & $0.743^{* *}$ & 1 & & & \\
\hline & & 0.000 & 0.000 & & & & \\
\hline \multirow[t]{2}{*}{4} & Relationship- & $0.711 * *$ & $0.791 * *$ & $0.808^{* *}$ & 1 & & \\
\hline & & 0.000 & 0.000 & 0.000 & & & \\
\hline \multirow[t]{2}{*}{5} & EI & $0.818 * *$ & $0.829 * *$ & $0.859 * *$ & $0.866 * *$ & 1 & \\
\hline & & 0.000 & 0.000 & 0.000 & 0.000 & & \\
\hline \multirow[t]{2}{*}{6} & IWB & $0.534 * *$ & $0.657 * *$ & $0.429 * *$ & $0.648 * *$ & $0.666 * *$ & 1 \\
\hline & & 0.000 & 0.000 & 0.000 & 0.000 & 0.000 & \\
\hline
\end{tabular}

Table 1 shows a significant positive relationship between emotional intelligence and its components, self-awareness, self-management, social-awareness and relationship-management with innovative work behavior in managers. Therefore, the main hypothesis and sub hypothesis of 1,2,3,4 are approved.

Table 2

Regression analysis of multi variables on the predictor components of emotional intelligence to predict the innovative work behavior

\begin{tabular}{ccccc}
\hline Model & $\mathrm{R}$ & $\mathrm{R}^{2}$ & $\mathrm{~F}$ & Sig \\
\hline 1 & 0.729 & 0.531 & 82.408 & 0.000 \\
\hline
\end{tabular}

Regression analysis has been used to express the rate of innovative work behavior in terms of emotional intelligence components, that in view of Table 2, the value of $F=82.408$ statistic and sig. is less than 0.05 , which indicates that there was a significant linear relationship between the components of emotional intelligence and innovative work behavior. The value of $\mathrm{R}^{2}$ determination coefficient also indicates that the obtained model expresses 53.1 percent changes of innovative work behavior.

Table 3

Coefficient equation for multivariable regression

\begin{tabular}{lccccc}
\hline Independent Variables & $\mathrm{B}$ & Std. Error & Beta & $\mathrm{t}$ & Sig. \\
\hline (Constant) & 17.861 & 0.242 & & 3.789 & 0.000 \\
Self-awareness & 0.195 & 0.079 & 0.221 & 2.853 & 0.001 \\
Self-management & 0.340 & 0.078 & 0.370 & 3.193 & 0.001 \\
Social-awareness & 0.094 & 0.062 & 0.176 & 1.488 & 0.003 \\
Relationship-Management & 0.230 & 0.085 & 0.246 & 2.965 & 0.001 \\
\hline
\end{tabular}

In addition, considering the Beta coefficient in Table 3, the variable of self-management has had maximum effect in predicting the innovative work behavior followed by relationship-management, self-awareness and social-awareness have been the effective variables.

\section{Discussion and Conclusion}

Four variables of relationship management, self-awareness, social-awareness and self-management have been considered as the components of emotional intelligence in this research, by studying and revising the previous literatures in the field of emotional intelligence and the relations of these variables were investigated with innovative work behavior. The research results have indicated that the emotional intelligence and its components had positive and significant relationships with innovative work behavior. Orhan and Dinçer (2012) also concluded the same in their research. The results obtained by regression analysis indicated that the variable of self-management had the most 
effect in assessing the variables of innovative work behavior followed by management, selfawareness and social awareness. Therefore, the bank managers to increase the innovative work behavior must exert particular attention to the components of emotional intelligence, especially on the variable of self-management. In addition, the investment and considerable budget allocation should be taken place for nurturing and fostering the thinkers and innovators among the senior managers. First, perhaps it seems, that it will relatively increase the budget and needs more time, but on the other hand it has positive outcomes for organization.

\section{References}

Rahim, M. A., \& Minors, P. (2003). Effects of emotional intelligence on concern for quality and problem solving. Managerial Auditing Journal, 18(2), 150-155.

Aghaei Fishani, T. (1999). Innovation and creativity in human beings, Termeh publication.

Bar-On, R. (2004). Emotional quotient inventory: A measure of emotional intelligence: Technical manual. MHS.

Baron, R. \& Parker, D.A. (2000). Emotional Intelligence Theory, Development Assessment at Home, School and in the Workplace, San Francisco.

Bradberry, T., \& Greaves, J. (2006). The emotional intelligence quick book: Everything you need to know to put your EQ to work. Simon and Schuster.

DeJong, J. P. J. (2007). Individual innovation: the connection between leadership and employees' innovative work behavior. EIM.

Orhan, N., \& Dinçer, H. (2012). Relationship between emotional intelligence and innovative work behaviors in Turkish banking sector. International Journal of Finance \& Banking Studies, 1(1), 2128.

Dulewicz, V., Higgs, M., \& Slaski, M. (2003). Measuring emotional intelligence: content, construct and criterion-related validity. Journal of Managerial Psychology, 18(5), 405-420.

Goleman, D. (2006). Emotional intelligence. Random House LLC.

Hayashi, A., \& Ewert, A. (2006). Outdoor leaders' emotional intelligence and transformational leadership. Journal of Experiential Education, 28(3), 222-242.

Janssen, O. (2000). Job demands, perceptions of effort-reward fairness and innovative work behaviour. Journal of Occupational and organizational psychology, 73(3), 287-302.

Kobe, L. M., Reiter-Palmon, R., \& Rickers, J. D. (2001). Self-reported leadership experiences in relation to inventoried social and emotional intelligence. Current Psychology, 20(2), 154-163.

Mumford, M. D., Scott, G. M., Gaddis, B., \& Strange, J. M. (2002). Leading creative people: Orchestrating expertise and relationships. The Leadership Quarterly, 13(6), 705-750.

Nwokah, N. G., \& Ahiauzu, A. I. (2010). Marketing in governance: emotional intelligence leadership for effective corporate governance. Corporate Governance, 10(2), 150-162.

Rezaeiyan, M., \& KoshtehGar, M. (2009), Relation Study between emotional intelligence and organizational commitment. Message of Management, 27, 27-39.

Salovey, P., \& Mayer, J. D. (1989). Emotional intelligence. Imagination, cognition and personality, 9(3), 185-211.

Samadi, A., \& Keyvan, N. (2013). A study on emotional intelligence of teachers in establishing the effective communication. Governmental Management, 1, 129-148.

Steiner, G A. (2007). The Creative Organization, Chicago: The University of Chicago Graduate School of Business Administration.

Zeinivand, A. (2009). A study on relationship of emotional intelligence and the performance of teachers of middle school, Juebar town, unpublished M.A thesis, Islamic Azad University, Sari branch. 